\title{
Medications Used for Acne Vulgaris: Practice Trends and the Use of Topical Combination Products
}

\author{
Robin E. Schroeder · Scott A. Davis · Michelle M. Levender · Steven R. Feldman
}

To view enhanced content go to www.combitherapy-open.com

Received: December 20, 2011 / Published online: February 2, 2012

(c) The Author(s) 2012. This article is published with open access at Springerlink.com

\section{ABSTRACT}

Introduction: Acne is a common disease caused by multiple factors affecting the pilosebaceous follicles. As a result of the multifactorial nature of this disease, current treatment guidelines recommend using drugs from multiple classes. Adherence is a challenge when multiple drugs are needed in a treatment regimen. Newer combination products may help physicians combat this issue. The purpose of this paper was

R. E. Schroeder · S. A. Davis · M. M. Levender •

S. R. Feldman $(\bowtie)$

Department of Dermatology, Wake Forest University

School of Medicine, Medical Center Boulevard,

Winston-Salem, NC 27157-1071, USA.

Email: sfeldman@wakehealth.edu

\section{S. R. Feldman}

Center for Dermatology Research, Department of Pathology, and Department of Public Health Sciences, Wake Forest University School of Medicine, WinstonSalem, NC, USA

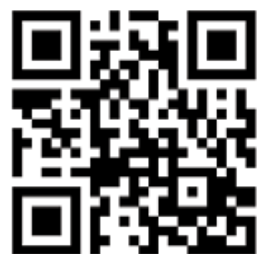

Enhanced content for Combination Products in Therapy articles is available on the journal web site: $w w w . c o m b i t h e r a p y-o p e n . c o m$ to examine prescribing patterns in the treatment of acne focusing on combination-product use.

Methods: The National Ambulatory Medical Care Survey database was queried for visits for acne. Visits were analyzed for patient demographics and treatment regimens. Prescription for common treatments and combination products were analyzed to determine changes in prescribing over time.

Results: The most common treatment for acne was topical retinoids. Two combination products were within the top 10 acne treatments. The use of combination products is increasing in primary care specialties $(1.26 \%$ per year; $P=0.002$ ) as well as among dermatologists $(0.66 \%$ per year; $P<0.001)$. Primary care physicians (12.6\%) prescribed combination products at a higher percentage of visits than did dermatologists (11.5\%).

Conclusion: The use of combination acne products is increasing. The use of combination products is expected to increase as a means of reducing treatment complexity and increasing adherence to treatment.

Keywords: acne; acne treatment; combination acne treatment; topical acne treatment; topical combination products 


\section{INTRODUCTION}

Acne vulgaris is an inflammatory condition occurring in more than $85 \%$ of adolescents with over $40 \%$ having persistent acne into their twenties and some continuing into adulthood $[1,2]$. Acne impairs quality of life and is associated with increased rates of depression, anxiety, and other psychological disorders [3-6]. Treatment is challenging in part because the pathophysiology of acne is complex. The disease is caused by multiple factors affecting the pilosebaceous follicles including: (1) alterations in keratinization; (2) follicle colonization with Propionibacterium acnes, which induces in ammation through toll-like receptors on in ammatory cells; (3) release of in ammatory mediators into the skin including matrix metalloproteinases; and (4) increases in sebum production with oxidized lipids further stimulating the production of inflammatory mediators [7]. Consensus guidelines recommend the use of drugs from multiple drug classes to effectively combat the different causative factors of the disease $[7,8]$. Treatment includes topical retinoids to address comedones, antibiotics to decrease $P$. acnes counts and reduce inflammation, and benzoyl peroxide to help prevent development of resistant bacteria $[9,10]$.

Adherence to topical medications is poor compared to oral medications, and acne medication adherence may be particularly poor in adolescent patients [11-13]. Patients may perceive topical acne medications as time consuming, messy, or inconvenient. Patients are challenged by incorporation of medication application into their daily routine, and may become discouraged when their acne does not improve quickly. Furthermore, out-of-pocket costs for topical medications may be high, and patients may be unwilling to pay for a medication that they recognize as ineffective [14].
Treatment failure may necessitate progression to more costly and potentially toxic therapies, such as oral antibiotics, hormonal therapy, or isotretinoin [8]. The need to utilize multiple products to address the different components of the pathogenesis of acne adds to the burden of treatment and the challenge of adhering to the treatment regimen.

Simplifying the treatment regimen, which can be accomplished with the use of combination products, improves adherence resulting in better outcomes for patients $[15,16]$. The purpose of this study was to assess the common treatments employed by prescribers, including dermatologists and primary care physicians. The authors assessed the number of individuals undergoing treatment for acne by each group and determined the most commonly used treatment regimens. The authors also focused on the use of combination products by both groups to determine whether the use of these products is changing over time.

\section{MATERIALS AND METHODS}

The National Center for Health Statistics (NCHS) conducts the National Ambulatory Medical Care Survey (NAMCS) to provide reliable information regarding the provision and use of medical care services in the United States. Data collection includes surveys completed by nonfederally employed outpatient health centers directly involved in patient care. Participating health centers are randomly assigned to a 1-week collection period in which patient visits are systematically randomly sampled. Sampled visits are logged by a physician provider and include patients' demographics, symptoms, physician's diagnosis, procedures performed, and medications ordered. After the data are collected, sampling weights are applied to the data in order to project national estimates of outpatient healthcare utilization [17]. 
In the present study, to assess the acne treatment practices of physicians in the United States, the NAMCS database was queried to identify all patient encounters from 1989-2009 in which a sole diagnosis of "acne" was recorded; visits with multiple diagnoses were excluded in order to assure that identified medications were prescribed for the treatment of acne. The data were also restricted from 2007-2009 to determine recent trends. The NAMCS database included both prescription and over-the-counter treatments discussed, dispensed, administered, and/or prescribed during the patient encounter. The authors compared prescribing patterns between dermatologists and primary care specialties, including family medicine, pediatrics, and internal medicine. The demographics of the patients seen by the different specialties were determined. The authors compiled the top 10 most prescribed acne medications; similar products were added together if there were more than one listing for the same generic chemical.

Regression analyses were performed to assess prescribing patterns over time, from the years 1989-2009. All data analysis was performed using SAS software (SAS Institute, Cary, NC, USA) and linear regression models were generated using SAS PROC SURVEYREG (SAS Institute).

\section{RESULTS}

There were an estimated 139 million patient visits for acne with 81.9 million patient visits with a sole diagnosis of acne from 1989-2009. Acne visits that had a sole diagnosis of acne were more common among dermatologists (66.7\%) than among primary care physicians (35.3\%). Dermatologists $(84.8 \%)$ saw the majority of these patients; family physicians $(7.2 \%)$, pediatricians $(4.8 \%)$, and internal medicine physicians (2.9\%) saw the other
$15 \%$ of patients. Visits for acne were more common among female patients among all specialties included in this study (Table 1). The most common age for treatment among dermatologists, family physicians, and pediatricians was between 10-19 years, and the most common age for treatment for the internal medicine physicians was between 20-29 years (Table 1).

The most commonly used acne medications in dermatology were tretinoin, isotretinoin, minocycline, adapalene, and tetracycline (Table 2). The products prescribed by the primary care specialists were different; however, tretinoin remained the number one treatment prescribed by both groups. Notably, dermatologists prescribed adapalene in $11 \%$ of patient visits and it was the fourth most commonly prescribed acne treatment, but it was not among the top 10 medications prescribed by primary care physicians. The top five prescribed acne treatments used by primary care specialties included the combination product erythromycin 3\% and benzoyl peroxide 5\%, whereas the top eight treatments used by dermatologists do not include any combination products. Both groups have two combination products, erythromycin 3\% with benzoyl peroxide $5 \%$ and clindamycin $1 \%$ with benzoyl peroxide $5 \%$ within the top 10 drugs prescribed for acne treatment.

In over 9.6 million patient encounters, a combination medication was prescribed from 1989-2009. Primary care physicians (12.6\%) prescribed combination products at a higher percentage of visits than did dermatologists (11.5\%; Table 3). The frequency of prescribing a combination product increased over time for both dermatologists $(P \leq 0.001)$ and primary care physicians $(P=0.002)$. The upward trend in the use of combination products from 1989-2009 is higher among primary care physicians at $1.26 \%$ per year compared to $0.66 \%$ per year among dermatologists (Fig. 1). 
From 2007-2009, primary care physicians (33.8\%) prescribed combination products at a higher percentage of visits than did dermatologists (22.0\%). For primary care physicians $(P=0.38)$, there was a downward trend in the use of combination products of $11.4 \%$ per year and for dermatologists $(P=0.66)$ there was an upward trend of $1.5 \%$ per year. The top five products used by dermatologists from 2007-2009 were isotretinoin, tretinoin, adapalene, clindamycin and benzoyl peroxide, and doxycycline. Similarly, the top five products used by primary care physicians were tetracycline, tretinoin, doxycycline, clindamycin and benzoyl peroxide, and erythromycin and benzoyl peroxide (Table 2).

\section{DISCUSSION}

During the study time-period, dermatologists managed most of the patients with a sole diagnosis of acne. The treatment selections by dermatologists and primary care physicians were not drastically different. This study found the use of topical combination products to be increasing for both dermatologists and primary care physicians. Both groups are employing this form of treatment in approximately $11 \%$ of their acne patients. The rate of increase per year was greatest among the primary care providers but both groups show a steady increase in use over the study period.

Table 1. Demographic information as NAMCS percentages in patient visits with acne as sole diagnosis from 1989 to 2009 by gender, race, and age.

\begin{tabular}{lllll}
\hline & Dermatology & Family medicine & Pediatrics & Internal medicine \\
\hline Gender & & & & \\
Female & 62.64 & 54.18 & 55.57 & 62.13 \\
Male & 37.36 & 45.82 & 44.43 & 37.87 \\
\hline Race & & & & \\
White & 85.4 & 83.49 & 71.06 & 91.85 \\
Black & 5.99 & 4.66 & 18.03 & 3.87 \\
Asian & 4.23 & 6.16 & 7.79 & 4.28 \\
Other & 4.38 & 5.69 & 3.12 & 0 \\
\hline Age (years & & & & \\
$0-9$ & 0.75 & 1.53 & 16.39 & 0 \\
$10-19$ & 50.2 & 67.77 & 81.5 & 34.10 \\
$20-29$ & 25.46 & 17.38 & 0 & 37.96 \\
$30-39$ & 14.20 & 8.97 & 0 & 19.79 \\
$40-49$ & 6.65 & 2.04 & 0 & 4.39 \\
$50-59$ & 1.62 & 2.30 & 0 & 2.31 \\
$60-69$ & 0.54 & 0 & 2.12 & 0 \\
$70-79$ & 0.40 & 0 & 0 & 0 \\
$80-89$ & 0.16 & 0 & 0 & 0 \\
$90+$ & 0.01 & 0 & & \\
\hline NAMCS & & 0.45 & \\
\hline
\end{tabular}

NAMCS=The National Ambulatory Medical Care Survey. 





Table 3. Use of combination products by dermatologists and primary care physicians, 1989-2009.

\begin{tabular}{llll}
\hline Product name & $\begin{array}{l}\text { Year first introduced to } \\
\text { the US market }\end{array}$ & $\begin{array}{l}\text { Total dermatology visits, \% } \\
\text { (total number prescribed) }\end{array}$ & $\begin{array}{l}\text { Total primary care visits, \% } \\
\text { (total number prescribed) }\end{array}$ \\
\hline $\begin{array}{l}\text { Erythromycin 3\% and benzoyl } \\
\text { peroxide 5\% }\end{array}$ & $26 / 10 / 84$ & $6.3(4,386,337)$ & $7.9(962,511)$ \\
\hline $\begin{array}{l}\text { Clindamycin 1\% and benzoyl } \\
\text { peroxide 5\% }\end{array}$ & $21 / 12 / 00$ & $4.7(3,265,092)$ & $4.6(567,937)$ \\
\hline $\begin{array}{l}\text { Clindamycin phosphate 1.2\% } \\
\text { and tretinoin 0.025\% }\end{array}$ & $7 / 11 / 06$ & $0.4(314,320)$ & 0 \\
\hline $\begin{array}{l}\text { Adapalene 0.1\% and benzoyl } \\
\text { peroxide 2.5\% }\end{array}$ & $8 / 12 / 08$ & & $0.4(45,647)$ \\
\hline
\end{tabular}

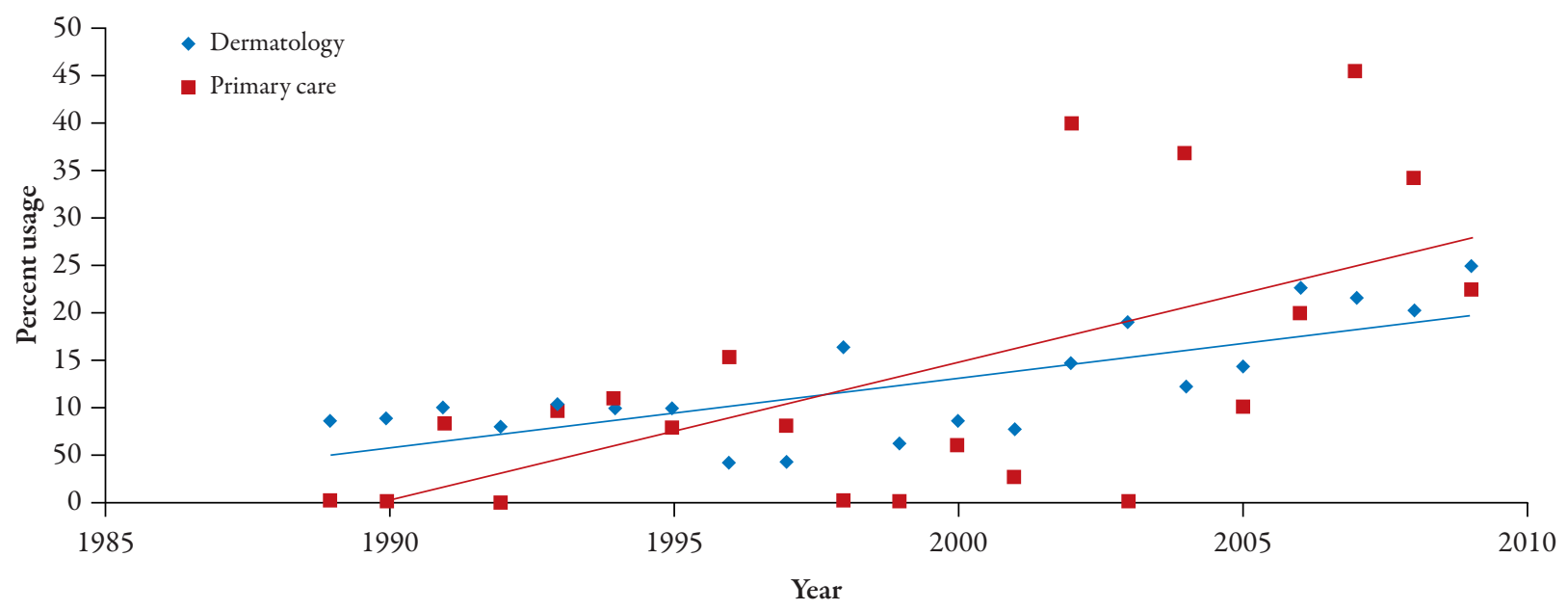

Fig. 1. Trends in the use of topical combination medications for the treatment of acne, 1989-2009.

The top treatment by each group was topical tretinoin therapy. Topical retinoids were considered first-line therapy in acne treatment during the study period and some still consider topical retinoids to be the best first-line therapy for mild to moderate acne [16]. However, a recent review article by Webster found that in nine studies comparing topical combination therapy to retinoid monotherapy, topical combination therapy was more effective at reducing the acne lesion counts in eight of the nine studies [10]. Combination products with benzoyl peroxide also decrease the incidence of antibiotic resistance. In a study by Cunliffe et al. [18] 40 patients received combination treatment and 39 patients received topical antibiotic monotherapy. At the end of 16 weeks of treatment, the $P$. acnes count and the clindamycin-resistant $P$. acnes count were significantly reduced in the combination treatment group when compared to topical clindamycin monotherapy [18]. Combination products reduce the necessity of prescribing multiple topical medications and simplify the treatment regimen. The advantages of combination products must be weighed against 
the greater exibility of using separate agents and the higher cost of combination versus monotherapy or multiple product regimens.

There are several limitations of this study using the NAMCS database. The data were for visits with the sole diagnosis of acne. Primary care physicians and dermatologists often bill for multiple problems during a visit. Thus, the data under represents the true number of acne cases treated by both groups. The data were restricted in this way to increase the likelihood that the medications prescribed at the visit were for acne treatment. Another limitation of the data is that the severity of the acne was not established, so treatment differences by severity could not be ascertained.

The final limitation in this study is that in recent years, many insurance companies have refused to cover the cost of topical combination medications. Combination products can be more expensive than the active ingredients prescribed separately; while the combination products have the advantage of reducing treatment complexity and improving treatment outcomes, the higher cost may have a significant impact on prescribing patterns of these products in the future.

In conclusion, despite these limitations, the graphical presentation of the data from 1989-2009 shows a clear picture of combination product use for acne over time. The use of combination products for acne is increasing among providers. The increased utilization of combination products may be secondary to improved availability over time and increased marketing of these products to patients and prescribers. Current acne treatment guidelines state that several drug classes should be used in the treatment of acne vulgaris $[7,8]$. Although the increased utilization of combination products may be due, in part, to greater availability and marketing of these products in recent years, the authors anticipate that this trend will continue because of the growing awareness of the need to use both topical retinoids and antimicrobial products and of the problem of poor adherence to complex acne treatment regimens. Combination product use improves efficacy and compliance compared to separate agents $[11,15,19]$. Combination products allow physicians to adhere to current acne treatment guidelines while prescribing a product that reduces application time and simplifies the treatment regimen when compared to prescribing two topical medications.

\section{ACKNOWLEDGMENTS}

The Center for Dermatology Research is supported by an educational grant from Galderma Laboratories, L.P. Steven R. Feldman is a consultant and speaker for Galderma, Connetics, Abbott Labs, Warner Chilcott, Centocor, Amgen, Photomedix, Genentech, Biogenidec, and Bristol-Myers Squibb. He has received grants from Galderma, Connetics, Astellas, Abbott Labs, Warner Chilcott, Centocor, Amgen, Photomedix, Genentech, Biogenidec, Coria, Pharmaderm, Dermatology Foundation, American Society of Dermatologic Surgery, National Psoriasis Foundation, Ortho Pharmaceuticals, Aventis Pharmaceuticals, Roche Dermatology, 3M, Bristol-Myers Squibb, Stiefel, GlaxoSmithKline, and Novartis, and has received stock options from Photomedix. Robin E. Shroeder, Scott A. Davis, and Michelle M. Levender have no con icts to disclose. Steven R. Feldman is the guarantor for this article, and takes responsibility for the integrity of the work as a whole.

Open Access. This article is distributed under the terms of the Creative Commons Attribution Noncommercial License which permits any noncommercial use, distribution, and reproduction in any medium, provided the original author(s) and source are credited. 


\section{REFERENCES}

1. Balkrishnan R, Kulkarni AS, Cayce $\mathrm{K}$, et al. Predictors of healthcare outcomes and costs related to medication use in patients with acne in the United States. Cutis. 2006;77:251-255.

2. Collier CN, Harper JC, Cafardi JA, et al. The prevalence of acne in adults 20 years and older. $\mathrm{J}$ Am Acad Dermatol. 2008;58:56-59.

3. Ayer J, Burrows N. Acne: more than skin deep. Postgrad Med J. 2006;82:500-506.

4. Dunn LK, O'Neill JL, Feldman SR. Acne in adolescents: quality of life, self-esteem, mood, and psychological disorders. Dermatol Online J. 2011;17:1.

5. Fried RG, Webster GF, Eichenfield LF, et al. Medical and psychosocial impact of acne. Semin Cutan Med Surg. 2010;29:9-12.

6. Yazici K, Baz K, Yazici AE, et al. Disease-specific quality of life is associated with anxiety and depression in patients with acne. J Eur Acad Dermatol Venereol. 2004;18:435-439.

7. Thiboutot D, Gollnick H, Bettoli V, et al. New insights into the management of acne: an update from the Global Alliance to Improve Outcomes in Acne group. J Am Acad Dermatol. 2009;60:S1-S50.

8. Gollnick HP, Krautheim A. Topical treatment in acne: current status and future aspects. Dermatology. 2003;206:29-36.

9. Gupta AK, Lynde CW, Kunynetz RA, et al. A randomized, double-blind, multicenter, parallel group study to compare relative efficacies of the topical gels 3\% erythromycin/5\% benzoyl peroxide and $0.025 \%$ tretinoin/erythromycin $4 \%$ in the treatment of moderate acne vulgaris of the face. J Cutan Med Surg. 2003;7:31-37.

10. Webster GF. Evidence-based review: fixedcombination therapy and topical retinoids in the treatment of acne. J Drugs Dermatol. 2011;10:636-644.

11. Dreno B, Thiboutot D, Gollnick H, et al. Largescale worldwide observational study of adherence with acne therapy. Int J Dermatol. 2010;49:448-56.

12. Krejci-Manwaring J, McCarty MA, Camacho F, et al. Adherence with topical treatment is poor compared with adherence with oral agents: implications for effective clinical use of topical agents. J Am Acad Dermatol. 2006;54:S235-S236.

13. Yentzer BA, Ade RA, Fountain JM, et al. Simplifying regimens promotes greater adherence and outcomes with topical acne medications: a randomized controlled trial. Cutis. 2010;86:103-108.

14. Storm A, Andersen SE, Benfeldt E, et al. One in 3 prescriptions are never redeemed: primary nonadherence in an outpatient clinic. J Am Acad Dermatol. 2008;59:27-33.

15. Yentzer BA, Gosnell AL, Clark AR, et al. A randomized controlled pilot study of strategies to increase adherence in teenagers with acne vulgaris. J Am Acad Dermatol. 2011;64:793-795.

16. Ghali F, Kang S, Leyden J, et al. Changing the face of acne therapy. Cutis. 2009;83:4-15.

17. Fleischer $\mathrm{AB}$, Jr., Feldman SR, White RE, et al. Procedures for skin diseases performed by physicians in 1993 and 1994: analysis of data from the National Ambulatory Medical Care Survey. J Am Acad Dermatol. 1997;37:719-724.

18. Cunliffe WJ, Holland KT, Bojar R, et al. A randomized, double-blind comparison of a clindamycin phosphate/ benzoyl peroxide gel formulation and a matching clindamycin gel with respect to microbiologic activity and clinical efficacy in the topical treatment of acne vulgaris. Clin Ther. 2002;24:1117-1133.

19. Lott R, Taylor SL, O`Neill JL, et al. Medication adherence among acne patients: a review. J Cosmet Dermatol. 2010;9:160-166. 